\title{
Multi-objective evolutionary algorithms for model neuron parameter value selection matching biological behavior under different simulation scenarios
} Tomasz G Smolinski* and Astrid A Prinz

Address: Dept. of Biology, Emory University, Atlanta, GA 30322, USA

Email: Tomasz G Smolinski* - tomasz.smolinski@emory.edu

* Corresponding author

from Eighteenth Annual Computational Neuroscience Meeting: CNS*2009 Berlin, Germany. 18-23 July 2009

Published: 13 July 2009

BMC Neuroscience 2009, I0(Suppl I):P260 doi:I0.I |86/I47|-2202-I0-SI-P260

This abstract is available from: http://www.biomedcentral.com/I47I-2202/I0/SI/P260

(c) 2009 Smolinski and Prinz; licensee BioMed Central Ltd.

In our previous work, we systematically explored a 12 dimensional parameter space of a 2-compartment model of the $\mathrm{AB}$ (anterior burster) neuron, which is one of the two cells that form the pacemaker kernel in the pyloric network in the lobster stomatogastric ganglion (STG). Our computational exploration started with a hand-tuned $\mathrm{AB}$ model [1] and systematically varied maximal conductances of membrane currents, one at a time with all the other conductances kept constant at their hand-tuned values, to determine ranges and variation steps that produced physiologically realistic behavior. Every parameter set representing an individual model neuron in this gridbased parameter space was simulated and classified as functional if it produced biologically realistic bursting activity. Specifically, we looked at the period, burst duration, spike and slow wave amplitude, number of spikes per burst, spike frequency, and after-hyperpolarization potential, which all had to be within limits determined in physiological experiments. Furthermore, in order to be classified as "good," the models had to exhibit proper responses to STG deafferentation (i.e., neuromodulator deprivation) as well as current injections both in the presence and in the absence of neuromodulation. After applying all the criteria, not only have we determined that many different parameter sets performed successfully under all tested conditions, but we have also found several very interesting relationships between parameters, which may indicate the existence of co-regulations in the investigated system [2]. However, the question has always remained: are the ranges determined by varying just one maximum conductance at a time suitable and representative of the solution space of the real AB neuron? Perhaps, if two or more conductances were varied at the same time, the ranges would have been different. Unfortunately, the answer to this question cannot be found by simply extending the ranges of parameter values to some arbitrary limits and simulating all the resulting combinations; this would be unrealistic computationally. Therefore, we utilize an approach alternative to the strict grid determination of the parameter search space, based on an application of Multi-Objective Evolutionary Algorithms (MOEA) to generate a population of neuron models meeting the above selection criteria. In MOEA, the algorithm searches for pseudo-optimal solutions by trying to optimize several, sometimes conflicting, objectives at the same time. In this case, all the selection criteria were implemented as separate objectives in the end-VEGA (elitist non-dominated Vector-Evaluated Genetic Algorithm), previously proposed by the authors [3]. The ranges of variation from the hand-tuned values were set between $-100 \%$ and $+400 \%$. This allowed for an extensive and ample exploration of the parameter space. The results from the simulation of the spontaneous activity alone [4], as well as all the remaining scenarios, on the one hand confirmed our observations about the possible existence of coregulations between some currents, but on the other hand, some of the relationships seen before seem to have disappeared over the extended ranges of values. This may indicate that 
some of the interactions observed with the grid approach were just local relationships. Conversely, the analysis of the expanded search space allowed for identification of relationships that were not seen in the previous stages of our study.

\section{Acknowledgements}

Support contributed by: Burroughs-Wellcome Fund CASI Award and NINDS ROI NS0549II-0IAI.

\section{References}

I. Soto-Treviño, et al.: Computational model of electrically coupled, intrinsically distinct pacemaker neurons. J Neurophysiol 2005, 94:590-604.

2. Smolinski, et al.: Systematic selection of model parameter values matching biological behavior under different simulation scenarios. BMC Neuroscience 2008, 9(Suppl I):P53.

3. Smolinski, Prinz, Zurada : Hybridization of rough sets and multi-objective evolutionary algorithms for classificatory signal decomposition. In Rough Computing: Theories, Technologies, and Applications Volume Chapter X. Edited by: Hassanien, et al. New York: Information Science Reference; 2007.

4. Smolinski, Prinz: Computational intelligence in modeling of biological neurons: A case study of an invertebrate pacemaker neuron. Proc International Joint Conference on Neural Networks Atlanta, GA 2009.

Publish with Bio Med Central and every scientist can read your work free of charge

"BioMed Central will be the most significant development for disseminating the results of biomedical research in our lifetime."

Sir Paul Nurse, Cancer Research UK

Your research papers will be:

- available free of charge to the entire biomedical community

- peer reviewed and published immediately upon acceptance

- cited in PubMed and archived on PubMed Central

- yours - you keep the copyright

Submit your manuscript here:

http://www.biomedcentral.com/info/publishing_adv.asp 